\title{
Students' Motivations to Study Abroad: The Case of International Students at the University of Debrecen
}

\author{
Jennyfer Paola Casas Trujillo', Peshawa Jalal Mohammed ${ }^{2}$, Sanaa Taler Saleh ${ }^{3}$ \\ Recommended citation: \\ Casas, J., Mohammed, P., \& Saleh, S. T. (2020). Students' motivations to study abroad: The case of \\ International students at the University of Debrecen. Central European Journal of Educational Research, 2(1), 76 - \\ 81.
}

\begin{abstract}
Today there is a growing demand among international students to study in Hungary, more specifically with the launching of Stipendium Hungaricum program in 2013. The number of international scholarship holders increases each year, but till now, we have no significant research results about their study motivations, research has focused only on institutional perspectives (Kasza, \& Hangyál 2018). The motivation of students is an important research field in higher education, particularly because there could be various factors to motivate students studying abroad. The motives can be categorised as intrinsic and extrinsic. Our research question is, what are the main intrinsic and extrinsic motivational factors that encourage students to study in Hungary? We performed 15 qualitative interviews among international scholarship holders on postgraduate levels. We gathered semi-structured interviews with the help of an interview scheme with five main questions. The investigated dimensions include the following: 1 . introduction and context of interviewees, 2. Reasons for leaving the country of origin, 3. Reasons for country choice, 4. Preliminary knowledge about Hungary, 5. Personal expectations. After the data collection, we analysed texts with open coding process in which line by line and word for word was analysed (Khandkar, 2009). Then we were able to form a typology of motivations and we found subcategories within the intrinsic and extrinsic classification.
\end{abstract}

Keywords: Motivation, international students, Debrecen

\section{Introduction}

This article attempts to contribute to the field of mobility. It is well known that there are major study destinations which historically have a preference for international students, places such as the US, the UK, Australia, Canada and New Zealand among others are in the top list of such destinations. However, in this article, we will focus on Hungary as an emerging destination.

Over the past years, Hungary's economy has demonstrated solid growth. The main source of income comes from foreign direct investment and the European Union (EU) funds, in order to cooperate with innovation activities (OECD, 2017). Since 2013 the Hungarian government launched the program Stipendium Hungaricum which has allowed Hungary to have the chance at receiving international students from abroad. This program is attractive to students due to the coverage in terms of fees and some aid support. This has become a new destination of interest, emerging compared to the five previously mentioned before and to some other non-English speaking countries. Apart from these five countries, there are predominant ones with strong economy such as Germany, France, Norway, etc. where people go to experience academic environment. Some of these places require students to know their national language. However, others offer programs in

\footnotetext{
1 University of Debrecen, Debrecen, Hungary; jennysita814@gmail.com

2 University of Debrecen, Debrecen, Hungary; peshawajalal@gmail.com

3 University of Debrecen, Debrecen, Hungary; sanasalh29@gmail.com
} 
English, as the case of Hungary, which attracts international students offering courses and programs in English and, besides its central location, there has been an increase in the numbers of foreigners from Asia and Africa, as well as South America.

The international exchange provides a give-and-take relationship in which internationals come and study and this contributes to the Hungarian economy. Also, students obtain their degrees and the experience to study in Europe. Most of the sending countries are developing ones and they can afford the cost due either to the reasonable cost of living or because of the opportunity to apply through scholarships. Nevertheless, this is a new program and every year the number goes up, which could mean that Hungary will become a strong recruiter of international students.

\section{Background of the study}

The internationalisation of education is gaining importance in today's higher education system, projects to increase mobility are taking place and students from overseas wish to be part of this new cultural group (Beech, S. 2019). Since 2008, the number of international students has increased rapidly. Especially in Hungary since 2014, one year after launching Stipendium Hungaricum and countries like China and Turkey have become strong contributors. (Kasza, G., Hangyál, Z.,2018). The bologna process has two main objectives, one is to contribute to the development of multi-cultural skills, and the other is to increase educational quality. Interestingly, the findings of a study on how student mobility affects multi-cultural skills and educational quality demonstrated that increasing the number of students reduces quality (Mechtenberg, L \& Strausz,R., 2007). What this study will intend to achieve is to clearly demonstrate the different intrinsic and extrinsic motivation to choose Debrecen specifically. When checking the studies on international students' motivations, it was not a surprise that they are placed in other parts of the world, but rarely in Hungary. For instance one study offers insights into the motivations or choice criteria used by students currently enrolled at international branch campuses in Malaysia. Findings from a survey of 218 undergraduate and postgraduate students plus semi-structured qualitative interviews conducted with 18 students indicated that the motivations for studying at an international branch campus are a function of the combined pull-push factors (i.e. institution and academic reputations, marketability of the degree, low tuition fees compared to the home institution, low cost of living, safe country for study, similarity of education systems as well as cultural proximity) (Ahmad \& Buchanan, 2017).

There is a study which investigates the motivations of Chinese international doctoral students in science, technology, engineering and mathematics fields for undertaking a $\mathrm{PhD}$ abroad, and the external factors influencing this major life decision. Based on in-depth interviews with 35 Chinese international doctoral students from seven universities in four Australian states, the findings showed that enriching life experiences and self-cultivation emerged as the most prominent of personal inspirations. The choice to study abroad, though ultimately a personal decision, was influenced by a range of factors and particularly long-term cooperation between host and home institutions. Both academic and personal reputation of supervisors played important roles in the selection of host institutions (Yang et al. 2018). In this study, there is a sense of digging the intrinsic and extrinsic motivations. Nevertheless, in Hungary, the expectations and attitudes of international students have been studied asking them about different services that are offered while they are studying, concluding that they are satisfied. (Kasza, G., Hangyál, Z.,2018). However, there is no evidence of studies that document the motivation of students to choose Debrecen as their focus of studies from a clear perspective of intrinsic and extrinsic motivations. The development of this research requires the understanding of key concepts which will be explained in the following paragraphs.

\section{Research design and Methods}

To investigate the students' motivation to study in Hungary, a qualitative approach was adopted. The qualitative research aims to understand experiences and processes. Kalof, Dan and Dietz (2008) explained that "qualitative studies explore what causes what and focus on why people think and act as they do" (p.80). To collect the data, a semi-structured interview was used. It was 
collected through a multi-step snowball sampling strategy. The interviews allowed the researchers to understand better the thought processes of the participants and their motivations as they were asked. In line with the qualitative nature of the study, the forms of questions used during the interview were designed as open-ended questions and were based on verbal reports. As Fraenkel, Wallen, and Hyun (2012) explained, open-ended questions "permit qualitative analysis" (p. 11). Data collected through the interview were then qualitatively analysed.

As a data collection tool in qualitative research, interviewing is used as a technique that seeks to cover factual and meaningful experiences of research subjects (Kvale, 1996) by giving them the privilege to express their feelings, opinions, knowledge and values as they experience them. The information given by the participants in an interview provides meaningful word relationships that can then be interpreted (Kvale, 1996). Interviews carried out with individual participants were the primary sources of data for the present research. During the interviews, all the participants were asked the same questions, which were predetermined before the interview except where clarification was needed. Each interview session took around fifteen minutes. The questions allowed subjects to introduce themselves, extrapolate the personal motives leading them to study abroad; explain why they chose Hungary as their place of study and not the home country; answer how studying abroad may affect their future career path and explaining whether there is anything expected of them by family. We hypothesised that the international students seek a better quality of study abroad to develop their communication skills and to become more independent.

\subsection{Participants and setting}

The participants of the present study were international Master and Doctoral students at the University of Debrecen. The number of participants was 15 students (seven males and eight females). The participants were assigned based on their willingness to share in the data collection process and their ability in speaking English as the process needed verbal response. They were all international students, and their educational backgrounds varied.

\subsection{Data analysis}

After obtaining the data via the interviews with students, the interviews were transcribed, and themes began to emerge as early as the transcription process. The important sections of the data were marked when the researchers went through the text. To be more familiarised with the emerging themes, each interview was individually examined, and similar themes were clumped together and open coding was used as descriptive names were added. Coding is a key aspect of the analysing process and how researchers break down their data to make something new. The data clumps was compared to each other to find connections and similarities, and then it was marked with appropriate codes for further analysis. The data was analysed descriptively to reveal the motivations the students had to study abroad, more specifically in Hungary.

\section{Results}

The findings of this analysis indicate that the main motivational domains for the international students are: personal motives, geo-academic motives, financial motives, family and future expectations.

\subsection{Personal motives}

Participants thought that studying abroad helps them learn more about themselves while attempting to adapt to their new country and understand its traditions and cultures. They believed that studying abroad means maturing and gaining self-confidence and tests their ability to adjust to different situations and respond to new circumstances with their problem-solving skills. For example, Amine, 32, from Algeria, at the faculty of Medicine, about her decision to study abroad said "but in certain points in life you have to make big steps and be away from family and depend on yourself and this was one of them". Similarly, Cha, 26, from China, at the faculty of Business and Economics 
pointed out that he feels happy to study abroad because "this will allow me to see and consider the world from a different viewpoint" with new eyes. Another personal motive among the participants was the strong desire to travel. They thought the geographical location of Hungary, being located almost square in the middle of central Europe, would be helpful to fulfill that goal. For instance, Asma, 38 from Egypt, at the faculty of Natural Sciences mentioned that "Hungary is in Schengen area" and Ivan from Mexico, at the faculty of Social Sciences said "It is cheap to travel from Hungary to other countries in Europe, I want to see some countries around".

\subsection{Geo-academic motives}

One of the main aims that drove international students to study abroad was the chance to achieve a high level of education. They thought it would be a good opportunity to broaden their horizons and continue their studies in a better educational system. For example, Salah, 31, from Morocco, at the faculty of Humanities said "I had a master in cultural studies; basically the University of Debrecen is the best institute regarding cultural studies we have in Europe". Ahmad, 26, from Iraq, at the faculty of Natural Sciences explained that "education system back home does not meet my ambitions" Similarly Tyhoo, 35, from Nigeria, at the faculty of Agricultural Sciences pointed out "I think the education in my country is not enough for the challenges of today". They also preferred a European diploma as having it meant possessing great prestige. Amine from Algeria in regards to preferring the quality of Hungarian education over her home country's, said "if I have to choose again, I will not choose my country".

The participants also believed that one great advantage of studying abroad is the ability to develop their English language proficiency. Adeel, 27 from Pakistan, at the faculty of Engineering said, "English is the most needed language to my future", and Omed, 40, from Iraq, at the faculty of Law, expressed the "must" of English because the language makes your development easier.

\subsection{Financial motives}

The participants were insisting that financial support to study by the Stipendium Hungaricum program was a great motivation to determine their study. They thought that, however, parents usually had given them a lot of support, the financial support reduces their financial burden and family pressure. Salah, from Morocco, argued that" this bursary will allow me to focus more on my studies not working". Besides, the data showed that the financial support would provide them with more opportunities, as Ashraf, 27, from Morocco, at the faculty of Humanities said, "to attend the conference and introduce me to newly developed technologies".

\subsection{Family and future expectations}

It was found out that regardless of the nationality and age, most of the participants were strongly concerned about the family's expectations. The feeling of responsibility was high among them. It is worth mentioning, the ways they voiced their responses to family expectation were different. For example, Cha from China said "I am a free person, but yes my family expect good grades from me" and Ivan from Mexico said "I think yes, my family hope I would be successful". Their tones were different. Adeel from Pakistan who said "my family sacrificed for me, so I have to do the same". Similarly, Ashraf from Morocco said "my father died two years ago, and I am the oldest son, so I have to take care of family, so there is a family expectation I am the oldest". It seems the cultural background of the participants plays a significant role in the way they respond to expectations coming from their families.

Most of the students agreed that as a result of studying abroad, job opportunities could be enhanced. It qualifies students in a variety of ways like, using real-world experiences or having an opportunity to work with international companies. Only one of the participants argued that a future career path relies on their abilities and skills, not on where they study. Hassan, 29, from Jordan, at the faculty of Engineering said "it is somehow a shock when you root yourself out of the family to enter a new environment, culture and even language but that can help you work in different countries in 
the future". Adeel from Pakistan said "my experience helps me learn to appreciate all my successes and depend on myself. That is what we need for a future career".

\section{Conclusions}

The purpose of this research was to study the intrinsic and extrinsic motivations that cause individuals to participate in study programs abroad. It was hoped that this information would be obtained in an attempt to find the motives that initiate students to apply for a Hungarian Scholarship program, one of the programs through which a large number of students are accepted annually. By determining what motivates students to study abroad, it is possible to identify the factors of attraction that motivate students to apply for this scholarship. In our research method to explore students' motivation to study abroad, we relied on the interview instrument and on snowball samples to identify participants.

Students admitted that the prospects of the Hungarian Scholarship Program increased their desire to gain academic and educational experiences. They thought they could benefit from the expertise of European universities to develop their professional competencies. Thus, this was an energizing and motivating factor for participating in such a program.

The most influential factor in attracting students from all over the world to study in Hungary was the fact that the Hungarian scholarship is easy to obtain from other scholarships and the low cost of living, besides getting a degree in a European country, made it even more appetizing. International students rated the desire to develop and acquire language and seek a better quality of life to achieve a greater sense of independence as the most motivating factor for studying abroad. And due to Hungary's excellent geographical position, in central Europe, it makes it desirable to international students for its easy access to other European countries. A strong driving factor is funding the study for international students, as students have expressed the importance of free, high-quality education. International students showed that studying abroad allows them to enter different places, such as working in various companies to improve working conditions and open doors to global companies. It is worth noting that international students were interested in the expectations of their families because the positive expectations of their families generate a sense of responsibility.

In summary, the current results show that international students have different motivations to study abroad, and the results indicate that international students are excited to explore a new culture and country, to seek out adventure and to experience a new environment, as well as being more eager to join classes offered in Hungary. The results also show that international students are willing to study abroad to learn about the origins of European culture as well as to develop their language skills, learn a new language, to immerse themselves. Also, they can see famous sights in Hungary and in the surrounding nations, meeting other people as well as making use of experienced professors to develop their academic and professional skills and expertise.

For future research studies, we should adopt larger samples and a comparison method to be implemented among international students in postgraduate studies and undergraduate studies. Using more study tools besides the interview is also planned. Using a questionnaire can make the scientist be able to raise many questions and get more data. In the future, studies should focus on comparing international students who gained a Hungarian scholarship and on international students who did not, so as to determine the differences in motivation of the two groups.

\section{Research limitations}

Some limitations of the current research must be addressed. The first limiting factor was that the number of individuals in the research sample was relatively small, and this is related to the nature of the data collection method. A large number of students can take researching much further.

The second factor was that the study was limited to postgraduate students, and we did not have an opportunity to collect data among undergraduate students covered by the Hungarian scholarship system. Thus, we ought to ask many more questions related to the research using questionnaires to collect the research data. 
Funding: This research received no external funding

Acknowledgments: No additional acknowledgement.

Author Contributions: All authors contributed to the study conception and design. Conceptualization, J.C., P.M., and S.T.S..; Methodology, J.C., P.M., and S.T.S.; Formal Analysis, J.C., P.M., and S.T.S; Investigation, J.C., P.M., and S.T.S.; Writing - Original Draft Preparation and Review \& Editing, J.C., P.M., and S.T.S.

Conflicts of Interest: The authors declare no conflict of interest.

\section{References}

1. Ahmad, S., \& Buchanan, F. (2017). Motivation factors in students' decision to study at international branch campuses in Malaysia. Studies in Higher Education, 42(4), 651-668, DOI: 10.1080/03075079.2015.1067604

2. Beech, S. (2019). The Geographies of International Student Mobility. Spaces, Places and Decision-making. London: Palgrave Macmillan.

3. Fraenkel, J., Wallen, N., \& Hyun, H.H. (2012). How to design and evaluate research in education (8 the d.). Boston, MA: McGraw Hill.

4. Kalof, L., Dan, A., \& Dietz, T. (2008). Essentials of social research. London: McGraw-Hill.

5. Kasza, G., \& Hangyál, Z. (2018). Stipendium hungaricum scholarship holders' expectations and attitudes. Budapest: Tempus Public Foundation. Retrieved https://tka.hu/docs/palyazatok/stipendium_hungaricum_scholarship_holders_expectations_and_attitude s_web1902051556.pdf

6. Khandkar, (2009). S. Open Coding. Retrieved from: http://pages.cpsc.ucalgary.ca/ saul/wiki/uploads/CPSC681/opencoding.pdf

7. Kvale, S. (1996). Interviews: An introduction to qualitative research interviewing. London: Sage.

8. Mechtenberg, L., \& Strausz, R. (2007). The Bologna process: how student mobility affects multi-cultural skills and educational quality. International Tax and Public Finance, 15(2),109-130.

9. OECD (2017). Supporting Entrepreneurship and Innovation in Higher Education in Hungary. OECD Skills Studies. Paris: OECD Publishing. Retrieved https://www.oecd-ilibrary.org/docserver/9789264273344-en.pdf?expires=1587120692\&id=id\&accname=gu est\&checksum=52F1B2F19430DB0811B971159B30D6B7

10. Yang, Y., Volet, S., \& Mansfield, C. (2018). Motivations and influences in Chinese international doctoral students' decision for STEM study abroad, Educational Studies, 44(3), 264-278.

(C) 2020 by the authors. Submitted for possible open access publication under the terms and conditions of the Creative Commons Attribution (CC BY) license (http://creativecommons.org/licenses/by/4.0/). 